\title{
Study on the effect of dry-wet cycle on the dam slope stability
}

\author{
Wei $\mathrm{Ye}^{1, *}$, and Fu Heng $\mathrm{Ma}^{1,2}$ \\ ${ }^{1}$ Dam Safety and Management Department,Nanjing Hydraulic Research Institute, Nangjing \\ 210029, China \\ ${ }^{2}$ State Key Laboratory of Hydrology-water Resources and Hydraulic Engineering, Nangjing \\ 210029, China
}

\begin{abstract}
During the dry-wet cycle, the soil cracks and matrix suction change a lot, at this same time, the overall slope stability should be paid attention to. Therefore, in this paper, physical model tests in two different scales were conducted to study the crack development of the dam slope and the change of the matrix suction, and then the stability of the dam slope was analyzed. The results showed that for the whole dam slope, cracks were most likely to occur at the middle part of the upstream dam slope, and cracks were most developed at this area. The matrix suction at the middle part of the dam slope was the largest. In addition, although the cracks were repaired by the rainfall, the integrity of the soil with cracks was not as good as that before the drought. The pressure of the dam slope was no longer continuous and the upper pressure could not pass to the bottom of the slope. Therefore, local landslides may occur when the upper earth pressure was increasing.
\end{abstract}

\section{Introduction}

The change and variability of the global climate have increased the frequency and intensity of extreme hydrological events[1-2]. Influenced by that, the climate change in China has increased dramatically in recent years, and the drought is more frequent. According to statistics, from 2009 to 2010, southwest region suffered severe drought since the meteorological record. In the summer of 2013, there was a rare history of high temperature and little rain in most areas of the south of the Yangtze River. In 2014, Henan Province suffered the worst drought in 63 years. The northern parts and the midwest suffered a severe drought, resulting in that the water level of multiple reservoirs was close to the dead water level or below the dead water level. The extreme low water level and drying of the reservoir cause the dam slope to produce a large range of cracks. If the strong rainfall is followed, the hidden danger of the dam slope will appear.

In general, cracks after drought are most dangerous in the subsequent rainfall process[3]. Zhang[4] applied the catastrophe theory in modern nonlinear analysis to study the mechanism of sudden instability and progressive instability in mountain slope under the influence of rainfall infiltration. Considering the cracks under rainfall, $\mathrm{Yu}$ [5] constructed a

*Corresponding author: 1079053235@qq.com 
model to determine the position and depth of the cracks, and calculated the stability coefficient of the slope by the residual thrust method. Generally, the formation of the cracks originates from the dry-wet cycle, and the change of the matrix suction is the most important performance in this cycle. The change of matrix suction affects the shear strength of the soil, and has an important influence on the stability of the dam slope. At present, there are many researches on the relationship between the suction and the strength properties in the dry-wet cycle. The volume pressure plate meter was used to realize dehumidification and moisture absorption, and to prepare different soil samples. The shear strength under different suction conditions was tested through the direct shear test[6-7]. It was found that for different types of soil, the relationships between the matrix suction and the shear strength were different. Gong[8] found that during the dehumidification process, the shear strength of the specimens increased exponentially with the increase of matric suction. In the process of hygroscopic, the tendency of shear strength to decrease with the decrease of suction was obvious at the high suction range[9]. Besides, the relationship between the suction and the shear strength of the red clay was also influenced by the density of the soil. For the silty sand, when the water content gradually decreased, the contribution of matrix suction to soil shear strength did not always increase, and there was a "peak effect"[10]. Generally, for the earth dam and embankment slope, the environment is complex and they may suffer from multiple cycles. Therefore, combined with the result of three axis test of the unsaturated soil, the influence of suction on the variation characteristics of unsaturated clay was discussed by Zhang[11], through comparison test of repeated dry-wet circulation soil and original soil.

At present, researches on the influence of dry-wet cycle on the stability of dam slope were mainly based on the direct calculation of the safety factor of slope stability, or the influence of suction on the shear strength. Few studies have taken the effect of cracks in the dry-wet cycle on the matrix suction and the earth pressure into consideration. However, the earth pressure could directly reflect the state of the stress in the dam slope. Therefore, through small-scale model test, the relationship between dam slope cracking and matric suction was accurately reflected, and then through large-scale model test, the influence of cracks on the earth pressure was studied. Finally, a comprehensive analysis of the influence of dry-wet cycle on the stability of the dam slope was conducted.

\section{Physical model test in small scale}

The purpose of the model test in small scale was to learn about the development of cracks in the dam slope after drought, and to understand the relationship between the matrix suction and cracks.

\subsection{Test model}

The long arc xenon lamp and fan in the environment box were used to simulate drought, and the adjustable atomizing spray nozzle was used to simulate rainfall (as shown in Figure $1)$. 


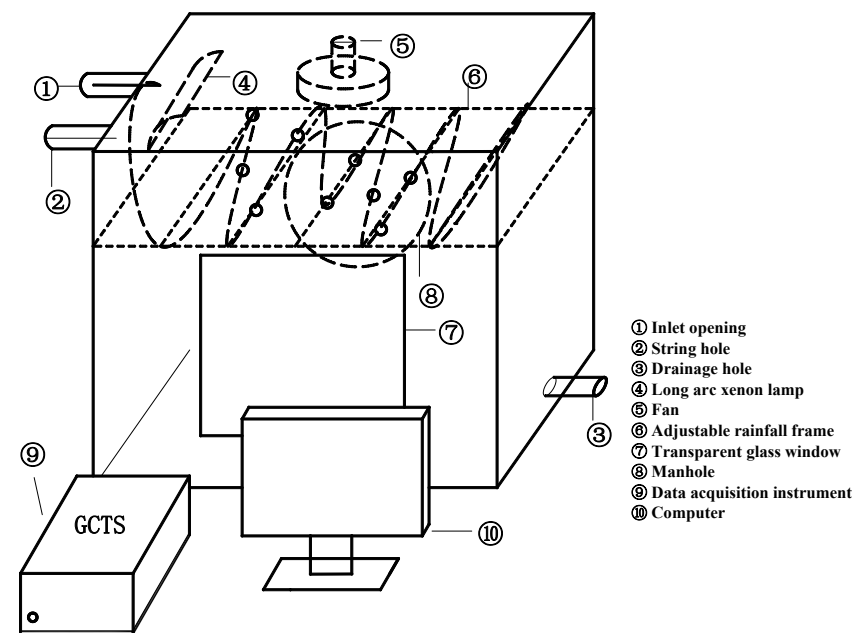

Fig. 1. Schematic diagram of the testing system.

The soil used in this study was excavated from the slope of the Baiguishan Reservoir dam (Henan, China). It consisted mostly of clay (23\%) and silt (46.8 \%), with some sand $(18.5 \%)$ and gravel fractions (11.7\%) (Figure 2). Its liquid limit and plasticity index were $30.8 \%$ and $17.1 \%$, respectively, and the optimum water content and maximum dry density were $19.2 \%$ and $1.4 \mathrm{~g} / \mathrm{cm}^{3}$, respectively. The non-uniform coefficient of the soil was 17.5 $(>5)$ and curvature coefficient was 0.914 (close to 1 ). The water content and density of the soil were shown in Table 1; the water content of the model was the same as that of the undisturbed soil. To meet the similarity criteria, the model was made to replicate the Baiguishan homogeneous earth dam at a ratio of 1:150 (as shown in Figure 3). The whole model was $25 \mathrm{~cm}$ in height, $130 \mathrm{~cm}$ long and $40 \mathrm{~cm}$ wide, and the upstream and downstream slope gradients of the model were 1:3 and 1:2, respectively. Four sensors used to measure suction were embedded at the dam heel, the middle of the upstream slope, the dam crest and the bottom of the model (as shown in Figure 3). The data collection during the test was automated, with researchers monitoring the collected data.

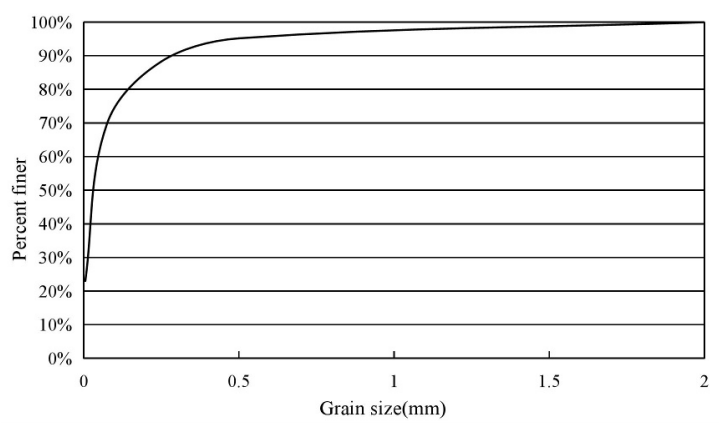

Fig. 2. Particle size distribution.

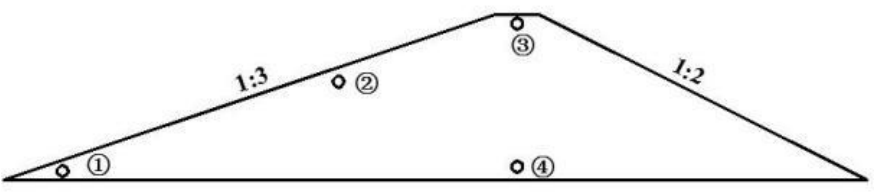

Fig. 3. Position of sensors. 
Table 1. Physical properties of the soil sample.

\begin{tabular}{|c|c|c|}
\hline Water content $\mathrm{w}(\%)$ & Wet density $\rho\left(\mathrm{g} / \mathrm{cm}^{3}\right)$ & Dry density $\rho_{\mathrm{d}}\left(\mathrm{g} / \mathrm{cm}^{3}\right)$ \\
\hline 18.1 & 1.65 & 1.40 \\
\hline
\end{tabular}

\subsection{Test analysis}

Three dry-wet cycles were conducted in the test, and the crack development in the dam slope in each cycle was shown in Figure 4.

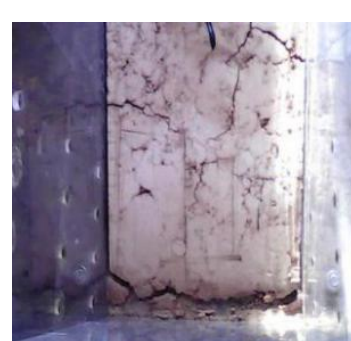

(a) First cycle

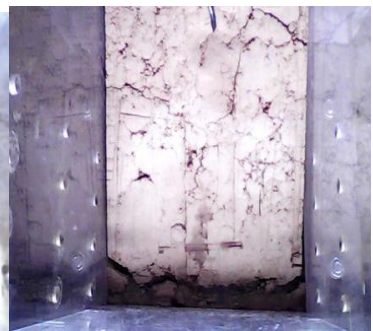

(b) Second cycle

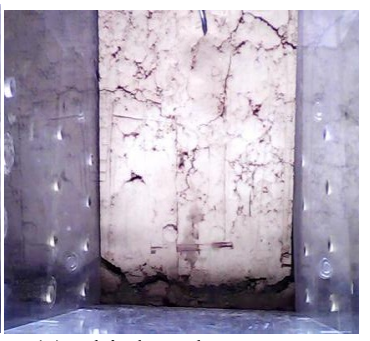

(c) Third cycle

Fig. 4. Crack development.

From the Figure 4, it was found that in the process of drought, cracks mainly occurred in the middle and the toe of dam slope. However, the toe of the dam slope contacted with the glass mold directly, and the soil layer of this part was too thin to reflect the actual engineering situation. Therefore, it could only be concluded that cracks were more likely to develop in the middle of the dam slope, and it could not determine whether the toe part was easy to crack.

The variation of matrix suction in each cycle was shown in Figure 5.

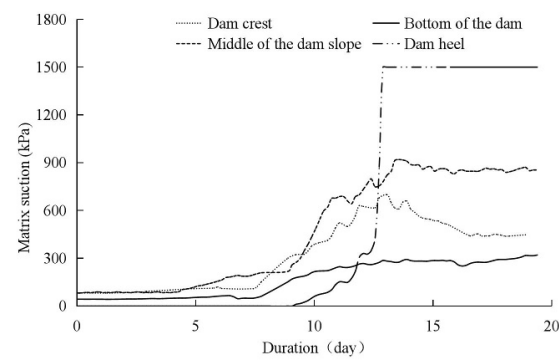

(a) First cycle

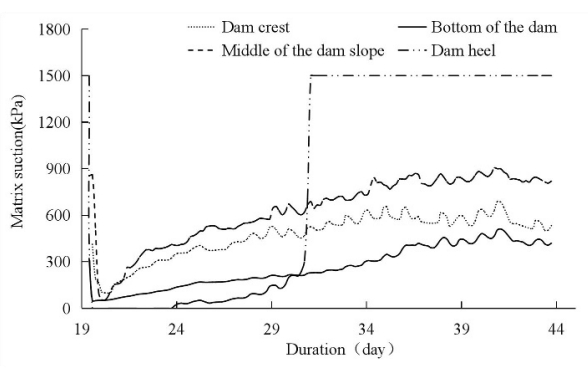

(b) Second cycle

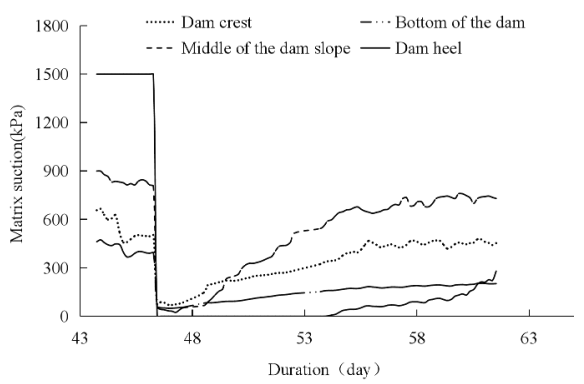

(c) Third cycle

Fig. 5. Matric suction measured at four locations on the dam model. 
There was no rainfall in the first cycle, and the drying process was conducted after the completion of the model filling. The simulation of the rainfall in the other two cycles were carried out based on last drying process. It could be found that in the rainfall process, there was a sudden drop in matric suction everywhere.

In each cycle, as the drought went on, the matrix suction at each part increased gradually. In the first cycle, at the beginning of drying, the water content at the toe of the dam gradually decreases with the progress of evaporation. However, due to the relatively low topography, water in the soil in the upper part of the dam slope infiltrated into the bottom, so that the water content at the dam toe decreased slowly. Therefore, the increase of the suction at the dam toe lagged behind that at the middle part of the dam slope. In the later period, the crack in the foot penetrated into the vicinity of the sensor, so that the sensor value reached the measurement range. In the second cycle, the overall moisture content of the model subjected to rainfall was much greater than that before the test. In addition, at the dam foot, during the drying process, the infiltration of water in other parts of the dam was much slower than the first time, eventually resulting in the suction at this site to reach extreme values a few days later.

The soil at the middle of the dam slope was the first to crack, and accordingly, the matric suction here was the first to grow rapidly. As the soil underwent a drying process, the original cracks which healed in the rainfall formed relatively quickly on the second drying process, which caused the dehydration in the upstream dam slope to be faster and the matric suction grew faster than the first time.

Comparing Figure 5(c) with Figure 5(b), it could be found that the test results of the third cycle were basically similar to the second.

Due to the appearance of cracks at the crest and the influence of the fan at the top of the environmental chamber, the dry cold wind entered the soil through the cracks. The external temperature had a great influence on the matric suction, and the change of the temperature caused the suction to fluctuate. When the drying process was carried out for more than ten days, the water content at the dam crest did not change much any more. At this time, the change of the matrix suction was mainly affected by the temperature. Reduced temperature, increased matric suction.

Because the cracks on the dam slope hardly affected the bottom of the dam, the matrix suction at the bottom increased slowly during each drying process. Comparing Figure 5(a) with Figure 5(b), it was found that in areas where the cracks were wide, the matric suction increased more quickly and the suction value was larger.

\section{Physical model test in large scale}

The purpose of this model test was to verify the law of crack development in the small scale model, and to obtain the change of earth pressure on the dam slope in the rainfall.

\subsection{Test model}

The soil used in this test was the same as the first test. The model was made at a ratio of $1: 28$. In order to save the amount of clay soil, the model was changed from a homogenous dam to a inclined wall dam. The dimensions of the model was shown in Figure 6. Earth pressure gauges were located at the bottom, middle and upper parts of the dam slope respectively. The test was conducted in a homemade environmental chamber which could be used for drought and rainfall simulations. (as shown in Figure 7). 


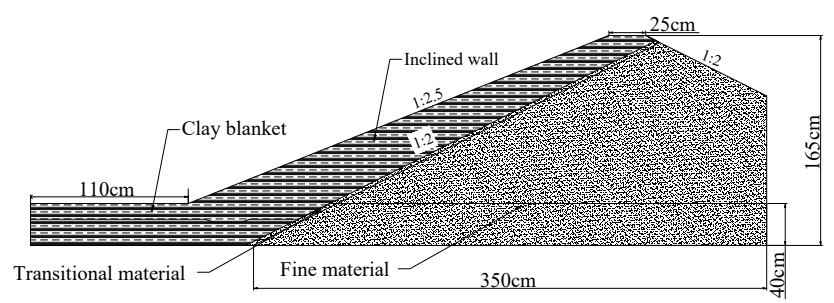

Fig. 6. Test model.

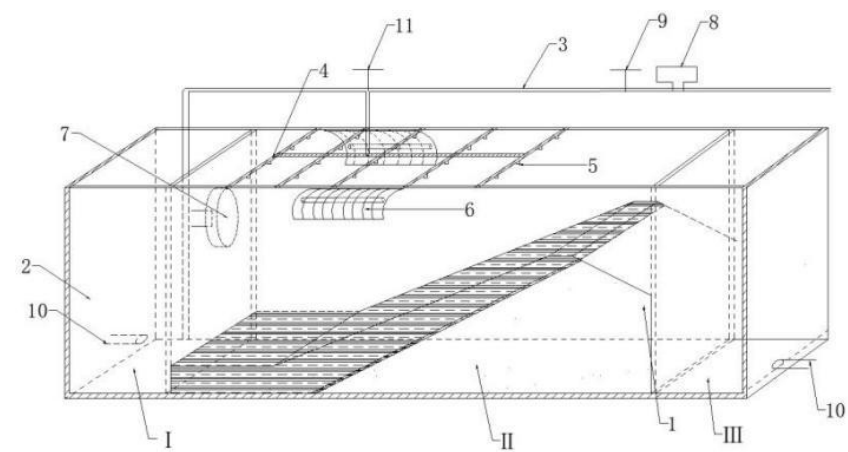

(1-Model of dam, 2-Tempered glass cover, 3-Water pipe, 4-Rain line, 5-Atomization nozzle, 6-Long arc xenon lamp, 7-Fan, 8-Booster pump, 9-Flow meter, 10-Drain hole, 11-Rainfall/Impound valve)

Fig. 7. Model system.

\subsection{Test analysis}

The test was conducted in three steps. The first was to impound water to form a stable seepage field in the dam body. The second was to simulate drought conditions to promote the development of cracks in the soil, and the third step was to simulate rainfall to create fluctuating drought-flood conditions.

In the first step of the test, the water level in front of the dam rose to $1.2 \mathrm{~m}$ firstly, and then remained unchanged for about 40 hours. Afterwards, the water was pumped out and the long arc lights and fans were turned on to simulate the drought. The temperature in the environment box was kept over $30^{\circ} \mathrm{C}$, and when the crack development of the slope is basically stable, the process of drought was stopped. The third step is to simulate rainfall, and through the rainfall, the water level rose gradually. The changes of the earth pressure were observes in each period.

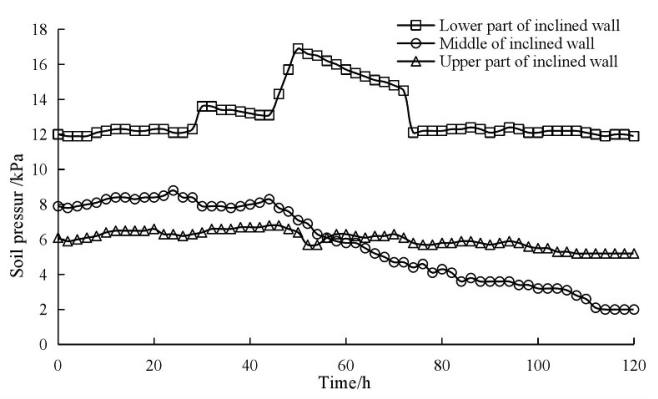

Fig. 8. Earth pressure in the first stage. 
It could be seen from Figure 8 that the earth pressure above the dam slope was basically maintained at a stable value in the beginning. After the initial impoundment, the soil in the middle of the dam slope was slightly collapsed and the soil layer loosened, resulting in a large change in the earth pressure value in the middle. The decreasing earth pressure showed that the stress in the middle was decreasing. For the lower part of the dam slope, the earth pressure was not affected by the wet settlement because it was far from the settlement joint. After the impounding, the moisture content of the soil changed greatly. The weight of the soil on the sensors increased, which increased the earth pressure, and then the water in the soil flowed out resulting in the decrease of earth pressure.

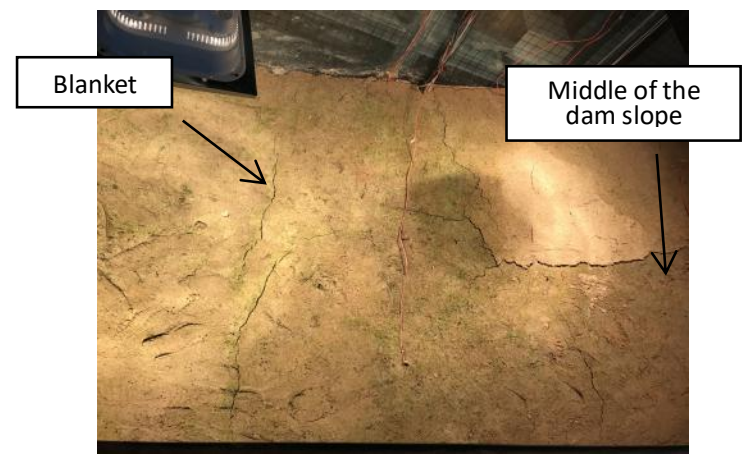

Fig. 9. Crack development.

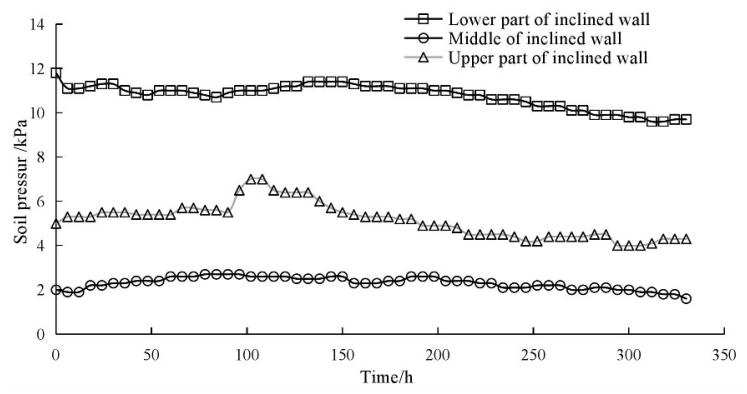

Fig. 10. Earth pressure in the second stage.

Compared with the development of cracks in the drying process in the small-scale model test, it could be found from Figure 9 that there were still many cracks in the middle of the dam slope, but there were relatively few cracks in the connection between the dam slope and the blanket (dam toe). Therefore, it could be considered that the middle of the dam slope was the most easily developed area for cracks. From Figure 10, it was found that the earth pressure was stable during the early stage of drying. As the drying process progressed, the earth pressure in the middle of the dam slope increased slightly. During the late drying period, due to the constant evaporation of water in the dam, the Earth pressure in each area were getting smaller and smaller. When the drying process was conducted for about 4 days, the water content of the dam body was measured artificially. At this time, because it was necessary to walk on the top of the dam to measure the water content artificially, the measured value of the earth pressure above the dam slope increased and then slowly decreased. There was no change in earth pressure in the middle of the dam slope, which indicated that the development of cracks had made it impossible for the upper earth weight to pass down. 


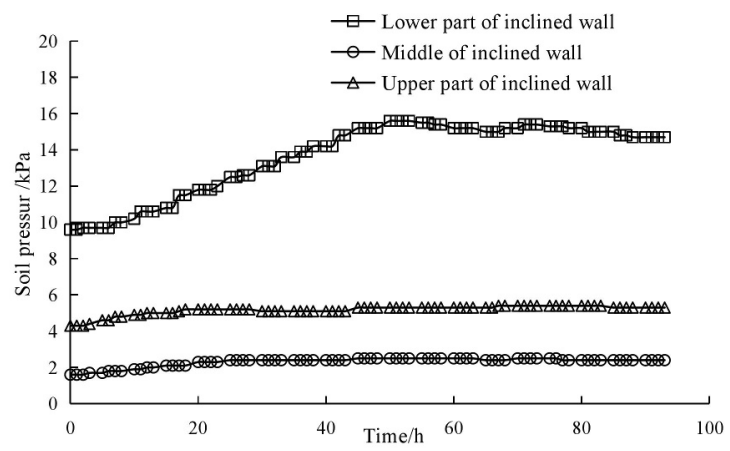

Fig. 11. Earth pressure in the third stage.

Earth pressure in the third stage was shown in Figure 11. After the rainfall, the earth pressure on the dam slope increased to varying degrees. The growth rate of the earth pressure at the bottom was the largest. In this process, the overall water content of the dam slope increased greatly, resulting in the weight of the soil to become larger. According to the calculation method of earth pressure, the earth pressure on the slope of the dam should have increased substantially with the weight of the soil. In the test, the bottom received most of the weight of the entire dam slope, where the earth pressure was the largest. The upper part bore less soil weight and the earth pressure value was small. The variation of the earth pressure in these two places conformed to the general law of changes of earth pressure. The variation of earth pressure in the middle part was smaller than that in the upper part. The occurrence of this phenomenon was attributed to the cracks in the drought. Due to the development of cracks, there was a phenomenon of unloading, which could not be calculated according to the general method of calculation. After the rainfall, the surface of cracks was healed. Although the soil appeared to be restored to a whole again, in fact, the integrity of the soil could not return to the state before the cracks were formed. Therefore, the earth pressure value was still small.

\section{Conclusion}

Based on physical model tests in two different scales, the development of cracks and changes of matrix suction and earth pressure in the dam slope during the dry-wet cycles were studied. The results showed that:

(a) For a clay dam slope, the middle part of the upstream dam slope was the most easily developed area for cracks, followed by the dam toe area. The appearance of cracks caused a great change in the suction, and changes in the matric suction were responsible for changes in the shear strength and the permeability coefficient of the soil. Therefore, the development of cracks made the characteristics of soil fluctuate greatly, which was worthy of the attention in practical engineering.

(b) For the middle of the dam slope where cracks were the most developed, the earth pressure was smaller than the upper part of the dam slope. Cracks in the middle of the dam slope made the soil no longer coherent. When the rainfall occurred, the upper soil gradually became saturated, which increased the weight of the upper soil. At this time, there was a risk of partial landslides. Although the cracks healed after the rainfall, the continuity of internal soil could not be restored to the state before the drought, which would seriously affect the stability of the dam slope. 


\section{Acknowledgements}

This work was financially supported by the National Natural Science Fund (51779155) and Project of Water Conservancy Science and Technology of He'nan Province, China (Grant No. GG201532, GG201546).

\section{References}

1. Ahmed A, Maddaus M. Understanding the Impact of Climate Change on Water Resources Sustainability-AWWA's Climate Change Committee Report[C]. World Environmental and Water Resources Congress, 2011:1347-1356.

2. Huang J, Makar P. Reclamation's Research on Climate Change Impact on Reservoir Capacity[C]. World Environmental and Water Resources Congress, 2013:1202-1212.

3. Zefeng J, Dayong Z. Critical slip field of slope with tension crack under intensive rainfall[J]. Rock and Soil Mechanics, 2016(s2):25-34.

4. Wohua Z, Helong C, Yunmin C. Catastrophe analysis for disaster of mountain slope stability affected by rainfall seepage and surface crack[J]. Journal of Zhejiang University(Engineering Science),2007, 41(9):1429-1435.

5. Tingting Y, Shengping G, Xuejie S. Stability Analysis of Reservoir Bank Slope Considering Tensile Crack by the Action of Rainfall[J]. Yellow River, 2017, 39(4):104-107.

6. Zhenghan C. Recent advances of the measuring technology for unsaturated soils and special soils[J]. Chinese Journal of Geotechnical Engineering, 2006, 28(2):147-169.

7. Fangzhi Z, Xiaoping C. Experimental Study on Characteristics of Deformation and Strength of Unsaturated Clay[J]. Chinese Journal of Rock Mechanics and Engineering, 2009, 28(a02):3808-3814.

8. Weibi G, Xiaowen Z, Wuhua Z. Test on suction and strength of expansive soil in a desorption-absorption cycle of moisture[J]. Chinese Journal of Geotechnical Engineering, 2006, 28(2):207-209.

9. Xinzhi L, Ming C, Xiaoyan C. The Influence of Matric Suction on Shear Strength Behavior of Unsaturated Laterites under Different Dry Densities[J]. China Rural Water and Hydropower, 2017(3):126-130.

10. Qian D, Long H, Baoyun Z. Influence of matric suction on shear strength of unsaturated silty sand[J]. Journal of Central South University, 2012, 43(10):4017-4021.

11. Zhangzhi Z, Xiaoping C. Influence of repeated drying and wetting cycles on mechanical behaviors of unsaturated soil[J]. Chinese Journal of Geotechnical Engineering, , 2010, 32(1):41-46. 